\title{
O CLIMA DAS CIDADES DO NORDESTE BRASILEIRO: CONTRIBUIÇÕES NO PLANEJAMENTO E GESTÃO URBANA
}

\author{
the climate of cities in Northeastern Brazil: \\ contributions in urban planning and management
}

\author{
Maria Elisa Zanella ${ }^{1}$ \\ Marcelo de Oliveira Moura ${ }^{2}$ \\ aaCaa
}

\begin{abstract}
Resumo
O presente texto trata de uma análise dos campos, métodos e técnicas empregados nos estudos de clima urbano desenvolvidos na região Nordeste do Brasil à medida que também traça reflexões sobre aplicabilidade dessas pesquisas no planejamento e gestão urbana nas cidades. Os campos de investigação do Sistema Clima Urbano de Monteiro (1976) serviram como estratégia de classificação para análise da produção científica. A consolidação dos estudos de clima urbano no Nordeste só ocorreu depois do ano 2000, tal ocorrência é fruto do fortalecimento da Pós-Graduação na região, que se amplia consideravelmente, principalmente em nível de doutorado. Constatou-se o predomínio de estudos sob o enfoque do campo térmico, os quais se deram na forma de episódios experimentais em campo, com escala predominantemente microclimática e com coletas horárias em pontos fixos no espaço urbano. Apesar do volume e da qualidade dos estudos contata-se a escassa aplicação dos mesmos nos planos de gestão urbana das cidades do Nordeste.
\end{abstract}

Palavras-chave: Clima Urbano. Campos e Técnicas. Planejamento Urbano. Região Nordeste. Brasil

\begin{abstract}
This paper brings an analysis of the fields, methods and techniques used in studies on urban climate carried out in Northeastern Brazil. In addition, we raise reflections on the applicability of those studies for urban planning and management in the cities. The research fields of the Urban Climate System by Monteiro (1976) served as classification strategy for the analysis of scientific production. The consolidation of the studies on urban climate in Northeast occurred only after the year of 2000. As such, this occurrence was a result of the strengthening of post-graduation in the region, which expanded considerably, particularly at the doctoral level. We observed predominance of studies addressing the thermal field, which were accomplished in the form of experimental episodes, with microclimatic scale predominantly and hourly collections at fixed points around the city. Despite the number and quality of the studies, it could be observed their limited application for urban management plans in the Northeast cities.
\end{abstract}

Key words:Key-words: Urban Climate. Fields and Techniques. Urban Planning. Northeastern. Brazil

\begin{abstract}
Resumen
Este artículo es un análisis de los campos, métodos y técnicas empleadas en los estudios de clima urbano desarrollado en el noreste de Brasil, como también rastros reflexiones sobre la aplicabilidad de esta investigación en la planificación y la gestión urbana en las ciudades. Los ámbitos de investigación del Clima Urbano Sistema Monteiro (1976) sirvieron como estrategia clasificación para el análisis de la producción científica. La consolidación de los estudios del clima urbano en el noreste se produjo sólo después de 2000, tal acontecimiento es el resultado de la consolidación de Postgrado en la región, lo que amplía considerablemente, sobre todo a nivel de doctorado. Encontramos un predominio de los estudios desde la perspectiva del campo térmico, que se administra en forma de episodios campo experimental con escala predominantemente microclimáticas y se recoge por hora en puntos fijos en el espacio urbano. A pesar de que el volumen y la calidad de los estudios es escasa aplicación de contactos en los planes de gestión de las ciudades urbanas del noreste.

Palabras clave: Clima Urbano. Campos y Técnicas. Urbanismo. Región Noreste. Brasil.
\end{abstract}

(1) Bolsista Produtividade do CNPq e Profa. Dra. do Programa de Pós-Graduação em Geografia da Universidade Federal do Ceará - Campus do Pici, Bloco 911, CEP: 60455-760, Fortaleza (CE), Brasil. Tel: (+55 85) 33669855 - elisazv@terra.com.br

(2) Prof. Dr. da Universidade Federal da Paraíba - Cidade Universitária, Campus I, CEP: 58051-900 - Joao Pessoa (PB), Brasil. Tel: (+55 83) 32167750 - geommoura@yahoo.com.br

\section{$a a_{a a}$}




\section{INTRODUÇÃO}

A cidade é a grande expressão geográfica da atualidade e sua importância espacial, demográfica, socioeconômica e cultural vem aumentando, o que mostra um mundo cada vez mais urbano. Tanto é que as cidades concentram, atualmente, a metade da população mundial, parcela que poderá aumentar para 70\% em 2050 (ONU, 2010). No Brasil as estatísticas afirmam que a população é majoritariamente urbana representando $84,4 \%$ da população do país (IBGE, 2011), e são nos espaços urbanos em especial nas médias cidades e nas metrópoles localizadas nos países não desenvolvidos que se manifestam de modo mais agudo os problemas de ordem ambiental, entre eles aqueles relacionados ao clima. A esta conjuntura agrega-se os problemas de natureza sanitária, serviços de saúde, emprego, renda, moradia e equipamentos de consumo coletivo que agravam ainda mais a qualidade de vida da população.

O clima constitui-se em uma das dimensões do ambiente urbano e sua alteração promove impactos sobre a saúde, o conforto e as atividades dos citadinos. A climatologia urbana se firma como área de saber de destaque na compreensão dessa problemática e seu estudo tem ofertado importantes contribuições à atenuação dos problemas socioambientais urbanos. Dessa forma, o estudo do clima das cidades se apresenta como campo de investigação fundamental a gestão do espaço urbano e, por conseguinte na melhoria da qualidade de vida das populações.

O planejamento urbano é o fator chave para reduzir os impactos e potencializar os aspectos positivos das alterações climáticas urbanas e os estudos de clima urbano têm fornecido informações e propostas importantes neste sentido, muito embora ainda sejam pouco aplicadas no âmbito do planejamento. No caso específico do Brasil, a abordagem de Monteiro (1976) trouxe essa preocupação ao propor o Sistema Clima Urbano (S.C.U), a partir do estudo das três áreas de aplicação tratadas dentro de uma abordagem sistêmica e de percepção, a saber: o subsistema termodinâmico (conforto térmico), o físico-químico (qualidade do ar) e o hidrometeórico (impacto pluvial), o que culminou na realização de inúmeros estudos nas diferentes regiões brasileiras.

No tocante ao campo de aplicação dos estudos de clima urbano realizados no Brasil, ganharam destaque aqueles relacionados ao subsistema termodinâmico, porém, a partir da década de 1990 ampliaram-se aqueles relacionados ao subsistema hidrometeórico, já que as cidades passaram a ter sérios problemas relacionados ao impacto das chuvas, com alagamentos nas áreas de alta impermeabilização e deficiente infraestrutura nos sistemas de drenagem e com inundações em ambientes localizados próximos aos cursos d'água, principalmente rios e lagoas.

Quanto ao campo de investigação ligado à poluição atmosférica, os estudos se concentram no principal eixo urbano/industrial do país (São Paulo - Rio de Janeiro - Belo Horizonte - Curitiba) conforme identificou Mendonça (2003) e Mendonça, Lima e Pinheiro (2012). Cabe mencionar que nos últimos anos houve uma intensificação dos estudos dos climas das cidades sob a perspectiva do estado de saúde-doença das populações urbanas, pauta de investigação presente nos grandes centros de pesquisa do mundo e do Brasil. Grande parcela desses estudos foi impulsionada ou desenvolvida sob a ótica do discurso das mudanças climáticas globais apresentadas pelo IPCC.

Muito embora na região Nordeste do Brasil os estudos de clima urbano tenham iniciado na década de 1980, estes cresceram consideravelmente a partir do início do decênio 2000, período no qual se ampliaram os programas de Pós-Graduação em Geografia na região, cujos temas de análise também se reportam aos problemas de ordem ambiental e da qualidade de vida nas médias e grandes cidades. Neste contexto o clima urbano passa a ser objeto de estudo em várias dissertações de mestrado e teses de doutorado, além de artigos científicos publicados em vários meios de divulgação.

Cabe considerar que muitos técnicos e profissionais que atuam no planejamento das cidades adentraram para as pós-graduações trazendo como objeto de suas pesquisas, os problemas urbanos que enfrentam o que faz da pós-graduação fundamental na formação de recursos humanos para as áreas de planejamento e gestão das cidades, inclusive na perspectiva da climatologia urbana. 
Existe dessa maneira um crescente interesse de se entender a repercussão negativa dos atributos climáticos no espaço urbano e por sua vez, os seus impactos gerados nas atividades e na vida dos citadinos, conhecimento que demanda por tecnologias cada vez mais sofisticadas a fim de se obter dados mais confiáveis ou mesmo representá-los adequadamente para que os mesmos possam servir de subsídios ao planejamento e gestão das cidades.

O objetivo central deste artigo é apresentar a distribuição espacial e temporal dos estudos de clima urbano desenvolvidos na região Nordeste do Brasil, destacando os campos de investigação do S. C. U proposto por Monteiro (1976), além dos métodos e técnicas empregados pelos estudos na região. Busca-se também traçar algumas reflexões sobre aplicabilidade destas pesquisas no planejamento e gestão urbana das cidades nordestinas.

\section{PÓS-GRADUAÇÃO EM GEOGRAFIA NO NORDESTE DO BRASIL E O FORTALECIMENTO DOS ESTUDOS DE CLIMA URBANO NA REGIÃO}

A pós-graduação sempre foi fundamental para a produção, ampliação e difusão do saber científico. Na geografia brasileira atual destaca-se a rápida expansão dos cursos de pós-graduação e, mais recentemente, denota-se um processo de descentralização dos cursos de pós-graduação que se instalam em estados do Nordeste, Norte e Centro-Oeste (SILVA, 2011). A região Nordeste conta atualmente com nove Programas de Pós-Graduação em Geografia stricto sensu conforme mostra a figura 1, onde também se visualiza a distribuição geográfica e a criação das modalidades dos cursos ofertados pelos programas de pós-graduação.

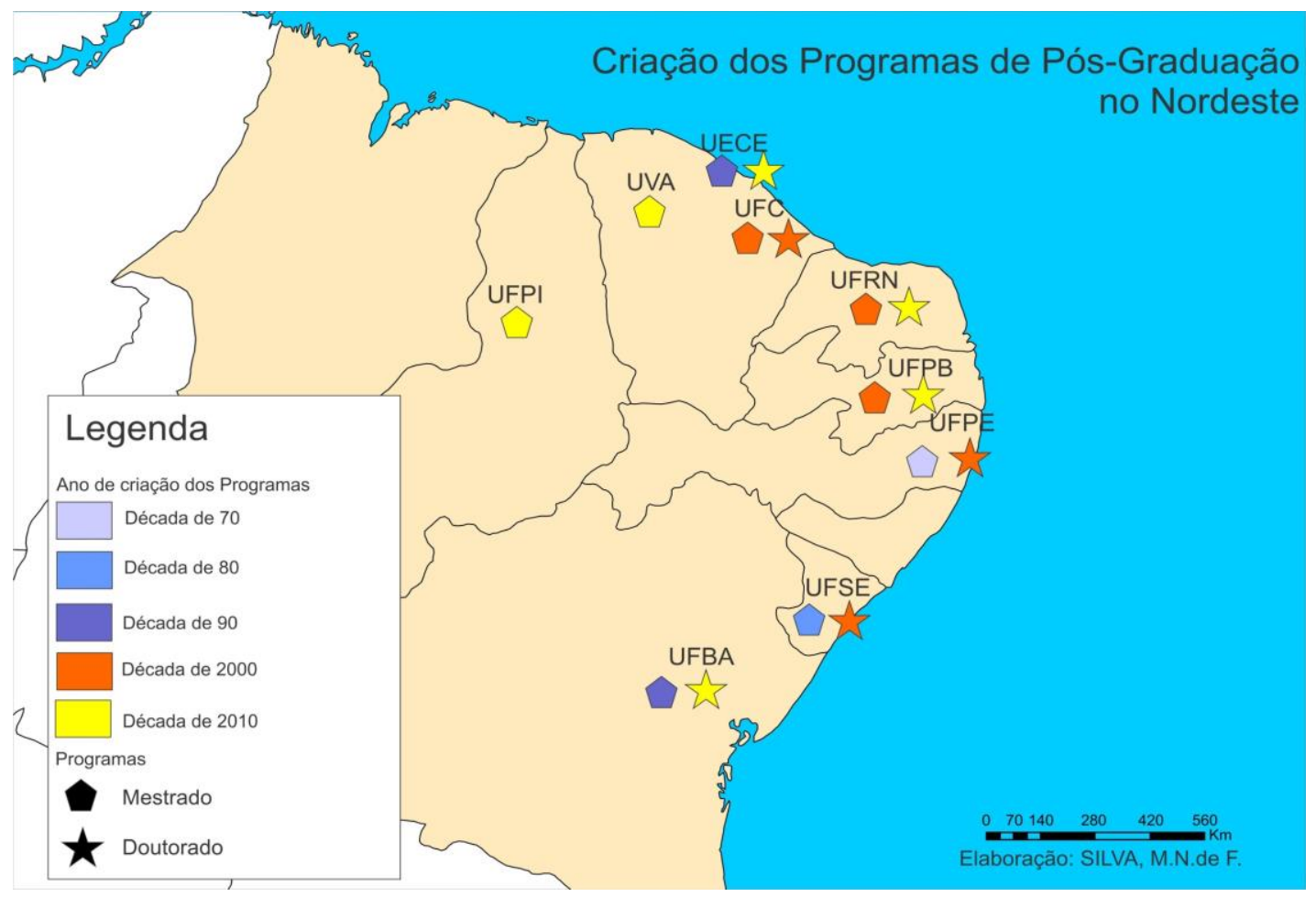

Figura 1 - Distribuição geográfica e criação dos Programas de Pós-Graduação em Geografia no Nordeste do Brasil. Fonte: BRASIL, 2013.

Na década de 1970, o Nordeste contava com apenas um programa de Pós-Graduação em Geografia; o mestrado da UFPE. Em 1985 é criado o mestrado de Geografia da UFSE, em 1994 o mestrado da UFBA e em 1996 o mestrado da UECE. É, contudo, a partir de 2000 que se ampliam consideravelmente os programas de Pós-Graduação em Geografia na região, principalmente a nível de doutorado. Assim, em 2000 é criado o doutorado da UFSE, em 2004 o mestrado da UFC, em 2003 o doutorado na UFPE, em 2008 o Doutorado da UFC, em 2010 o Doutorado da UECE 
e também o doutorado na UFBA, em 2011 o mestrado da UFPI e o Mestrado da UVA /Sobral e, finalmente, os doutorados da UFRN e UFPB em 2012.

A ampliação da pós-graduação se fez notar nos estudos e publicações em climatologia geográfica na região, a partir da área da Geografia, fortalecida pela criação de Grupos de Pesquisa nas Instituições Federais de Ensino. O clima de todas as capitais do Nordeste do Brasil conta com estudos de qualidade, que muito contribuíram para a sua compreensão. Se muitos estudos têm sido desenvolvidos no Nordeste, o mesmo não se constata a nível de aplicação dos mesmos.

A consideração de Andrade (2005, p. 75) de que "a aplicação da Climatologia no Planejamento das áreas urbanas é um objetivo apontado por quase todos os autores, [e que] a constatação da falta de aplicação é também muito frequente", é verificado para as cidades da região Nordeste. É lamentável que os gestores públicos ainda não tenham incorporado a dimensão dos climas urbanos nos planos de gestão, instrumentos estes fundamentais nos processos de planejamento urbano e por sua vez, na melhoria das condições e qualidade de vida da população urbana.

Nos planos diretores das cidades do Nordeste, a exemplo dos planos diretores dos anos de 2004 e 2009 da cidade de Fortaleza, o clima continua a ser definido e compreendido de modo bastante genérico, por meio somente das normais climatológicas de um único ponto da cidade. Muitos planos não consideram, portanto o fato de que o espaço urbano modifica a atmosfera próxima a ela produzindo uma diversidade de climas e tão pouco consideram que essa produção pode acarretar repercussões negativas e atingir de forma diferenciada a população, uma vez que, as repercussões das alterações climáticas ocorrem de forma seletiva no espaço urbano, devido principalmente à segregação socioespacial presente nas cidades, fenômeno este de acentuada expressão nas metrópoles do nordeste brasileiro.

Apesar do cenário exposto, existem estudos de clima urbano de autoria de geógrafos que trabalham como técnicos e planejadores urbanos que tentam a medida de suas limitações administrativas, efetivarem suas contribuições científicas junto aos planos de gestão urbana. Para exemplificar, no Programa de Pós-Graduação em Geografia da Universidade Federal do Ceará - UFC, pesquisas de ordem climática foram desenvolvidos por técnicos da Defesa Civil, da Secretaria do Meio Ambiente do Estado (SEMACE), da Prefeitura de Fortaleza, entre outras Instituições Públicas, o que poderá contribuir para que esse quadro possa mudar no futuro.

Destaca-se também, que quando há possibilidade dos resultados das pesquisas se tornarem conhecidas através da mídia televisiva ou por meio de reportagens de jornal impresso e online, quer seja pelos problemas apontados ou pelas propostas de soluções apresentadas, tornam-se uma ferramenta positiva de conscientização, dispositivo de auxílio à aplicação das pesquisas ao planejamento urbano, à proporção que as pesquisas tornam-se visíveis a sociedade civil e as ações de cobranças pelos citadinos aos seus gestores representantes poderão ser realizadas.

O enunciado nove da Teoria Clima Urbano (MONTEIRO, 1976) revela que as alterações dos elementos climáticos da cidade são passíveis de auto-regulação, cabendo ao homem urbano o papel dessa ação, através de seu poder de decisão, concretizado por meio do planejamento, o qual deve levar a incorporação do conjunto social, ideológico, científico e tecnológico. Monteiro (1976, p.102) aposta nesse instrumento e afirma que o clima da cidade dificilmente chegaria ao equilíbrio homeostático, devido à crescente desorganização do espaço urbano, porém, os gestores, junto com a sociedade, podem de forma consciente elaborar dispositivos de reciclagens necessários à condução dos controles climáticos urbanos.

\section{OS ESTUDOS DE CLIMA URBANO NO NORDESTE: CAMPOS E TÉCNICAS DE INVESTIGAÇÃO}

O Nordeste é destaque no pioneirismo dos estudos de clima urbano no Brasil, sendo a pesquisa de Sampaio (1981), em nível de mestrado, com o objeto de estudo o campo térmico na cidade de Salvador intitulada Correlações entre o uso do solo e ilha de calor no ambiente urbano: o caso de 
Salvador/BA, palco de um dos primeiros estudos de caso de clima urbano no Brasil. Também é válido mencionar o trabalho desenvolvido por Tarifa e Vasconcellos (1982) para a cidade de São Luís/MA na perspectiva do conforto térmico com avaliação do índice TEC (Temperatura Efetiva Corrigida).

A partir dos anos 2000 é que os estudos de clima urbano tornam-se mais expressivo na região Nordeste do Brasil. Cabe salientar que antes desse período houveram produções científicas relevantes realizadas por: Castro (1991), Melo (1991) e Vidal (1991) desenvolvidas para a cidade de Natal, no nível de mestrado, na área da arquitetura, aplicados ao campo térmico e do conforto humano; Gonçalves (1992) em Salvador no campo hidrometeórico/ inundações urbanas (Tese de Doutorado em Geografia Física) e por Santana (1997) em Fortaleza no campo térmico (Dissertação de Mestrado em Geografia Física). Acompanhando a expansão das pós-graduações em Geografia no Nordeste brasileiro, crescem as pesquisas e as publicações em diversas áreas da ciência geográfica, incluindo aquelas relacionadas à climatologia, principalmente a partir da virada do século XXI.

Em Fortaleza, já na década de 1990, têm-se os estudos do Projeto METROFOR (1990), Xavier (1996), Maia et al. (1996), Santana (1997) e de Malveira (1998), todos na linha investigativa do campo termodinâmico. A partir de 2000, destacam-se os trabalhos de Pétalas (2000), Zanella e Claudino-Sales (2002), Santana (2002), Malveira (2003), Moura (2006), Moura (2008), Moura, Sales e Zanella (2008), Moura, Zanella e Sales (2010), Paiva (2010), Leite e Silva (2010) e Paiva (2011) ambos pesquisando condições térmicas e/ou o conforto humano na cidade, pensados no sentido de fornecer subsídios ao planejamento urbano, e os de Zanella e Silva (2006) e Zanella, Sales e Abreu (2009) no campo hidrometeórico.

Diversos estudos sobre o clima urbano em cidades pequenas e médias do Ceará foram publicados em anais de eventos da área por integrantes do Grupo de Pesquisa em Climatologia Geográfica da UFC, resultados de pesquisas de iniciação científica, monografias de bacharelado, monografias de especialização e dissertações de mestrado. Ainda não existem trabalhos no campo físico-químico, muito embora se tenha um ensaio realizado por Mesquita e Granjeiro (2007) sobre a poluição do ar no Centro de Fortaleza e de Rocha et al. (2010) sobre a dispersão de poluentes e sua relação com os elementos climáticos na mesma cidade. Neste campo há muito que se explorar, cujas pesquisas começam a ser desenvolvidas junto ao Grupo de Pesquisa em Climatologia Geográfica da UFC associados a pesquisadores do IFCE.

Em Natal é proeminente os estudos de clima urbano na área da Arquitetura, destacando aqueles que investigaram as temperaturas e o conforto térmico no ambiente urbano, dos quais: Carvalho (2001), Oliveira e Silva (2005), Luna, Carvalho e Amaral (2006), Sousa, Luna e Carvalho (2006) e Costa, Silva e Bezerra (2009). Nesta mesma cidade têm-se também estudos realizados por profissionais da meteorologia a exemplo de Valadão (2010). Em se tratando da qualidade do ar merece destaque o trabalho de Alves e Silva (2009), sobre a poluição do ar nos principais centros comerciais de Natal. A cidade de Mossoró, localizada no semiárido do Rio Grande do Norte, também tem sido alvo de estudos em Climatologia Urbana, como a pesquisa desenvolvida por Saraiva, Grigio e Moura (2010) na identificação das ilhas de calor urbano.

Para Recife os estudos na área da climatologia urbana se concentram no campo térmico. Destaque são as pesquisas de Freitas (2004) e Moreira (2007), sobre as condições térmicas na metrópole e Pontes (2001) estudando a qualidade do ar de Recife. Ainda relativo às condições térmicas da cidade de Recife tem-se os estudos de Nóbrega e Vidal (2010), Nóbrega e Lemos (2011) sobre ilhas de calor e conforto térmico e Oliveira et al. (2011) investigando o impacto das chuvas na metrópole. Outros estudos são os de Moreira e Nóbrega (2011 a) e Moreira e Nóbrega (2011 b) fazendo uso de imagens orbitais na banda termal para identificação de ilhas de calor no espaço urbano de Recife.

Em João Pessoa os estudos relacionados ao clima urbano estão vinculados exclusivamente ao campo termodinâmico e foram desenvolvidos principalmente nos Programas de Pós- Graduação da UFPB (Engenharia Urbana e Arquitetura e Urbanismo) e UFCG (Meteorologia e Recursos Naturais) a exemplo das pesquisas realizadas por Duarte (2010), Souza (2010) e Santos (2011) que analisa- 
ram os padrões microclimáticos em diferentes setores urbanos da cidade e Peregrino (2005) que verificou o impacto da verticalização no escoamento dos ventos nos bairros da orla de João Pessoa.

Trabalhos no nível de graduação, como os de Almeida et al. (2011) e Silva et al. (2011) vinculados ao recente Grupo de Pesquisa em Climatologia Geográfica da UFPB estão sendo desenvolvidos na perspectiva de ampliar os conhecimentos sobre o clima local de João Pessoa. Na Paraíba o clima de outras cidades também foi objeto de pesquisas, os quais se destacam os estudos de Silva et al. (2005) e Júnior (2006) sobre as condições térmicas na cidade de Campina Grande e o trabalho de Silva et al. (2005) para a cidade de Patos.

Na cidade de Maceió os trabalhos foram desenvolvidos por profissionais da área da arquitetura e da meteorologia versando sobre o campo termodinâmico e o conforto humano em bairros e praças da cidade. Dessa forma, os estudos de maior relevância são os de Torres e Barbirato (2004) e Barbosa (2005). Destaca-se também o trabalho de Araujo (2006) sobre análise termal da superfície urbana de Maceió com uso de imagens orbitais. Em Aracajú tem-se um estudo que trata do clima local, embora num contexto climático mais amplo realizado por Pinto (2002). Em outra cidade sergipana, Itabaiana, um estudo sobre a percepção térmica da população quanto às áreas verdes foi elaborado por Santos e Pinto (2010).

Em Salvador os mais importantes estudos encontram-se na perspectiva hidrometeórica e foram desenvolvidos por Gonçalves (1992, 2003, 2004). No campo térmico merecem ressalva os trabalhos de Nery, Andrade e Moura (2006) e Moura et al. (2006) vinculados ao Laboratório de Conforto Ambiental do curso de Arquitetura e Urbanismo da UFBA que analisaram os padrões da morfologia urbana de Salvador na perspectiva do conforto térmico. Destaque para os trabalhos de Andrade e Santos (2006), Mendes, Silva e Gonçalves (2006 e 2007) e Andrade, Santo e Santos (2007) desenvolvidos na cidade de Feira de Santana com estudos de clima urbano relacionados às condições térmicas e o conforto humano.

Para Teresina, os estudos de evidência são aqueles sobre o campo térmico de Andrade (2000), cujas temperaturas do ar foram tratadas dentro de uma perspectiva cultural, por meio da representação do calor em Teresina, bem como a tese de doutorado do mesmo autor (ANDRADE, 2009) que tratou da análise de ambientes topoclimáticos na cidade. Outros estudos sob o nível do campo térmico, como os de Kallas (2008), Feitosa (2010) e Feitosa et al. (2011) também foram realizados na cidade de Teresina com o intuito de verificar as consequências da subtração da vegetação no aumento da temperatura local.

Em São Luís, destaque para os estudos de Araújo (2000 e 2001), Araújo e Sant’Anna Neto (2002), e Araújo et al. (2003) sobre o processo de urbanização na produção do clima urbano e Araújo (2009) sobre bioclimatologia e conforto térmico em São Luís. Com as orientações desse pesquisador outros estudos têm sido publicados a partir de 2010 sobre clima urbano de São Luís.

Dada a impossibilidade de relacionar todos os estudos de clima urbano das cidades nordestinas, algumas considerações gerais a respeito do clima urbano e a quantificação dos estudos foram levantadas, principalmente por meio de informações em anais de eventos, dissertações de mestrado, teses de doutorado e artigos em revistas que tratam sobre a temática. O presente levantamento aponta a existência dos trabalhos de Imamura-Bornstein (1991), Silva (1999), Bernardo (1999), Correa (2000), Sousa (2004), porém, não foi possível apresentá-los por razões de acesso.

Deve-se deixar claro que, por se tratar de um levantamento bibliográfico com uma escala espacial tão abrangente, o mesmo deixou à margem muitos trabalhos desenvolvidos, isso pela falta de conhecimento da existência ou acesso. Nas figuras 2, 3 e 4 encontra-se a distribuição quantitativa aproximada dos estudos de clima urbano no Nordeste do Brasil realizados a partir da década de 1980 nas três áreas de aplicação do S.C.U proposto por Monteiro (1976). Apesar de muitos trabalhos analisados não adotar a metodologia de Monteiro (1976) os mesmos foram classificados nos níveis de resolução que formam a estrutura do S.C.U, isto é, os campos termodinâmico, físico-químico e hidrometeórico. 
Os quantitativos apresentados nos mapas apontam que a perspectiva mais aplicada nos estudos de clima urbano no Nordeste é a do campo termodinâmico (total de 68 estudos), seguido dos campos hidrometeórico ( 8 estudos) e físico-químico (4 estudos). Esse esboço quantitativo para região Nordeste segue a mesma tendência nacional na escolha das abordagens das pesquisas em climatologia urbana tal como observou Mendonça (2003), Ely (2006), Fialho e Azevedo (2006) e Mendonça, Lima e Pinheiro (2012).

Também se observa nos mapas que as nove capitais nordestinas contam com estudos de clima urbano, embora com diferenças no número de pesquisas e nos campos investigativos, isso porque somente Fortaleza e Recife apresentaram estudos nos três campos do S.C.U, seguido de Natal e Salvador que além de possuírem pesquisas no campo térmico, apresentaram estudos aplicados, de modo respectivo, nos campos físico-químico e hidrometeórico, conforme mostra as figuras 3 e 4.

Cabe lembrar que os estudos apontados na quantificação foram realizados por três áreas do conhecimento; geografia, arquitetura e meteorologia, tendência observada em todo Brasil, conforme também identificou Lombardo (2008). Na área da arquitetura os trabalhos estão voltados principalmente ao conforto térmico, já os estudos da meteorologia envolvem modelagem e uso de imagens de satélites na obtenção de ilhas de calor e as pesquisas dos geógrafos estão relacionadas ao ambiente térmico e ao impacto das chuvas nas cidades, envolvendo, inclusive, a noção de risco e vulnerabilidade socioambiental.

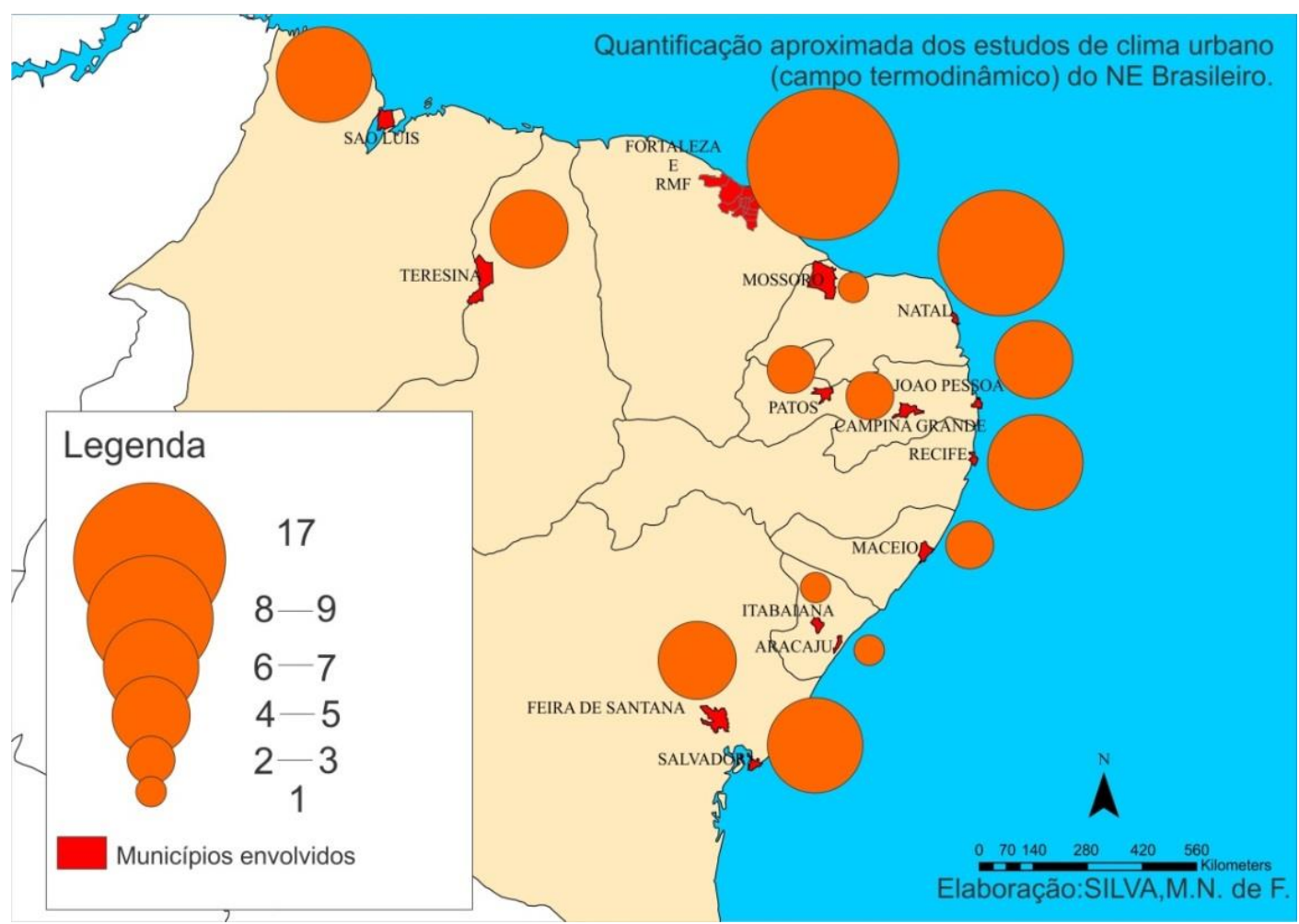

Figura 2 - Quantificação aproximada dos estudos de clima urbano no Nordeste: campo Termodinâmico. 


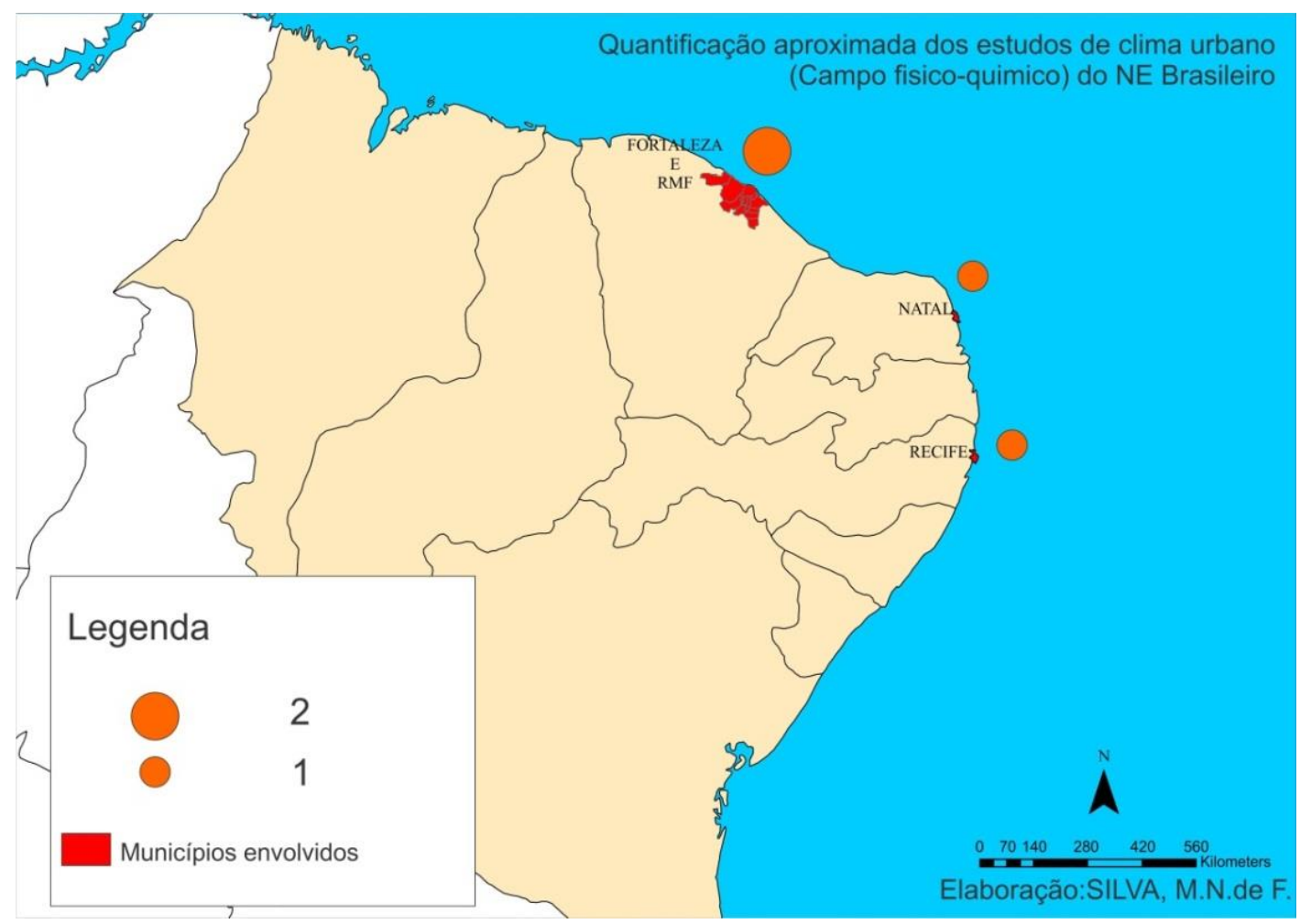

Figura 3 - Quantificação aproximada dos estudos de clima urbano no Nordeste: campo Físico-Químico.

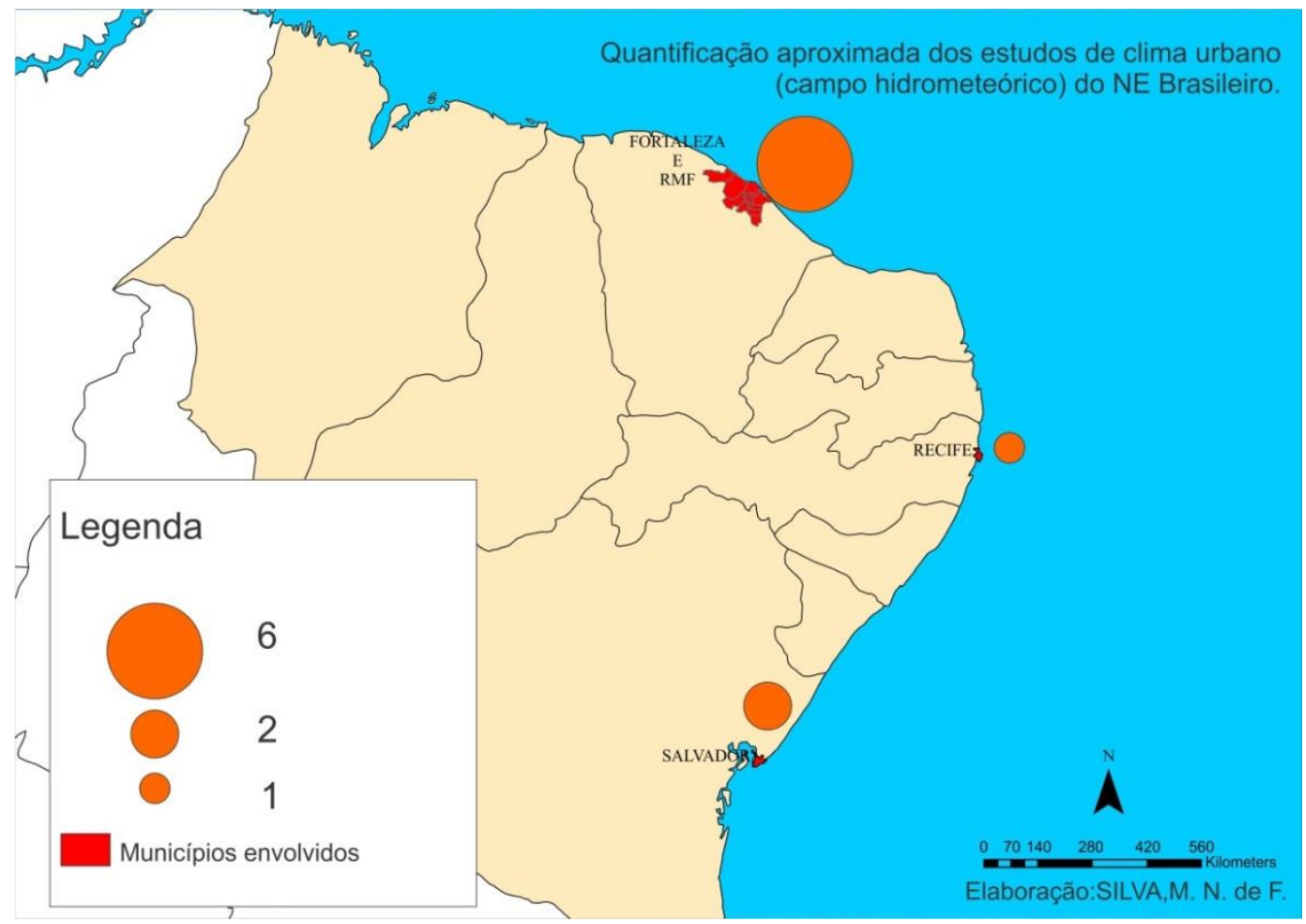

Figura 4 - Quantificação aproximada dos estudos de clima urbano no Nordeste: campo Hidrometeórico.

Na tentativa de destacar somente os trabalhos realizados na área da geografia foi elaborado um esboço das principais técnicas empregadas pelas pesquisas de clima urbano no Nordeste (Quadro 1). No levantamento foram consideradas teses de doutorado, dissertações de mestrado e trabalhos monográficos de autoria de geógrafos realizados a partir dos anos 2000, além de artigos com co- 
autoria de geógrafos ou elaborados por profissionais de outras áreas que atuam como docentes responsáveis pela disciplina de climatologia nos cursos de Graduação e Pós-graduação em Geografia nas Instituições de Ensino Superior do Nordeste.

Quadro 1- Técnicas empregadas nos estudos de clima urbano no Nordeste do Brasil.

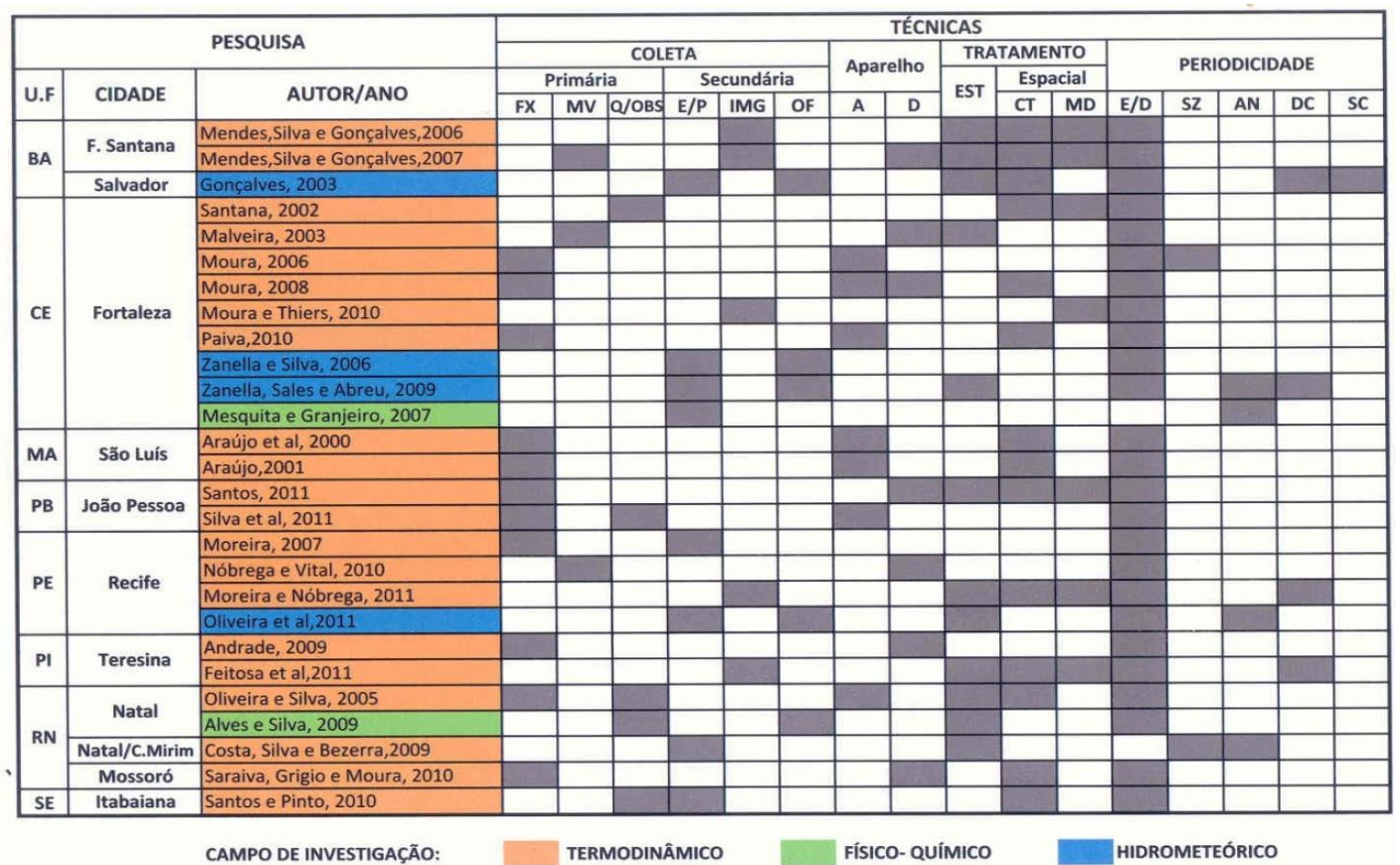

Legenda: COLETA: Primária (FX- mensuração fixa; MV- mensuração móvel/transectos; Q/OBS- aplicações de questionários ou outras observações realizadas em campo) e Secundária (E/P- estações ou postos pluviométricos; IMG- imagens de satélites (banda termal); OF- outras fontes, como instituições públicas (Governo Municipal e

Defesa Civil) e jornal impresso ou on line; Aperelho (A- instrumental analógico ou mecânico; D- sensores digitais); TRATAMENTO: (EST- estatístico; CT- cartografia temática, incluindo o emprego de isolinhas; MD- modelagem matemática ou computacional) e PERIODICIDADE: (E/D- episódico ou diário; SZ- sazonal; AN- anual; DCdecenal; SC- secular).

Com base no levantamento bibliográfico e com o uso das informações expostas no quadro 1, algumas considerações são destacadas sobre o estudo do clima nas cidades do Nordeste brasileiro:

a) a consolidação dos estudos de clima urbano no Nordeste só ocorreu depois do ano 2000, com numerosos trabalhos realizados em nível de Graduação e também da Pós-Graduação. Esse aumento é fruto do fortalecimento da Pós-Graduação na região, que se amplia consideravelmente, principalmente a nível de doutorado;

b) prevalecem às pesquisas aplicadas ao campo termodinâmico na forma de experimentos episódicos de campo, com escala espacial predominantemente microclimática, num nível que varia de 1 a 2 metros do solo, com coletas em pontos fixos e mensurações obtidas tanto por aparelhagem mecânica como por meio de sensores digitais. Todavia crescem os estudos que se utilizam de fontes secundárias no campo de investigação termodinâmico, principalmente com obtenção de imagens de satélites na banda termal, cujo tratamento da imagem se dá através de modelagem matemática e computacional;

c) a variável meteorológica mais abordada nos trabalhos é a temperatura do ar, com registros de diferenças térmicas positivas no espaço urbano variando de $0,5^{\circ} \mathrm{C}$ até $8,0^{\circ} \mathrm{C}$, com valor médio de $3,0^{\circ} \mathrm{C}$ (obtidas pelas pesquisas que realizaram levantamentos de campo). A maior 
diferença térmica positiva encontrada para as cidades do Nordeste foi detectada por Araújo et al. (2000) para a cidade de São Luís;

d) cidades de porte pequeno e médio como Campina Grande, Patos, Mossoró, Feira de Santana dentre outras, apresentaram diferenças térmicas positivas comparáveis com aquelas registradas nas cidades- metrópole, constatação essa que vai ao encontro com as colocações de Monteiro (1976), que afirma que a alteração no clima da cidade não depende do seu grau de urbanização;

e) os estudos realizados sob o enfoque do campo físico- químico e hidrometeórico utilizam exclusivamente dados de natureza secundária advindos das estações meteorológicas e/ou dos postos pluviométricos, além de fontes de órgãos públicos como, Secretarias Municipais, Defesa Civil e de jornal impresso ou on line. Não obstante existem algumas pesquisas que efetivaram aplicações de questionários com a população para avaliação de percepção de riscos ambientais urbanos;

f) nos estudos há o predomínio do uso de escala temporal curta (horária e diária), entretanto existem estudos que se utilizaram das séries históricas de estações meteorológicas e dos postos pluviométricos para análise de variância e tendência dos elementos climáticos, principalmente aqueles estudos ligados ao campo hidrometeórico;

g) a aplicação dos estudos de clima urbano é praticamente inexistente nas cidades nordestinas, tendo em vista outros interesses, principalmente o econômico. Assim, novas áreas vão sendo incorporadas à malha urbana, com supressão da vegetação, aterramento de corpos hídricos, aumento da impermeabilização, etc. ampliando os problemas ambientais urbanos, dentre eles os de ordem climática.

\section{CONSIDERAÇÕES FINAIS}

Dada a dimensão dos estudos de clima urbano das cidades do Nordeste brasileiro, é importante considerar que não se encerra aqui as considerações apontadas, pois se sabe que vários trabalhos não foram inclusos e que muito ainda precisa ser levantado para melhor se definir as características dos climas urbanos das cidades nordestinas. No entanto, deve-se destacar que todas as capitais do Nordeste possuem pesquisas de qualidade na área da climatologia urbana.

Em se tratando do instrumental utilizado nas pesquisas, observa-se que nos últimos anos ampliam-se as medições em aparelhos digitais, antes realizadas dominantemente por aparelhos analógicos. As imagens de satélites termais também vêm sendo incorporadas, principalmente nos estudos de ilhas térmicas. Além disso, a modelagem tem feito parte de alguns estudos do clima urbano, muito embora ainda no âmbito de meteorologia e da arquitetura. Há que se considerar o uso e a importância das geotecnologias no estudo do sítio urbano e na representação dos atributos e controles climáticos, tornando-se assim, ferramenta fundamental para o estudo do clima das cidades.

A aplicabilidade dos estudos de clima urbano ainda é inexpressiva. A escassa aplicação da climatologia no planejamento deve-se às dificuldades de comunicação entre pesquisadores e técnicos do planejamento, vontade política e, principalmente, interesses econômicos. No caso das capitais nordestinas, àqueles do setor imobiliário se destacam, já que a maioria delas tem enfrentado um processo de especulação imobiliário alarmante, com valorização de seus espaços urbanos, principalmente aqueles próximos ao mar, às áreas verdes ou ainda onde as condições de infraestrutura urbana apresentam-se consolidadas. Assim, os interesses desse setor econômico prevalecem, em detrimento do ambiente natural, cuja redução da cobertura vegetal, desmonte de dunas e aterramento de lagoas, entre outras alterações no sítio urbano são cotidianamente observadas.

Por fim, apesar da aplicação dos estudos de clima urbano nos planos de gestão das cidades nordestinas ocorra de forma retraída, esforços têm sido realizados por parte do meio acadêmico e mesmo por técnicos que atuam nos órgãos ambientais do governo no sentido de que as pesquisas 
sejam conhecidas e aplicadas pelos gestores públicos urbanos a fim de contribuir para melhorias das atividades cotidianas, de saúde e de maneira geral no conforto da população urbana.

\section{REFERÊNCIA BIBLIOGRÁFICA}

ALMEIDA, C. A. ET AL. Microclimas urbanos no centro de João Pessoa-PB. In: IV Simpósio Internacional de Climatologia. João Pessoa/ PB, 2011. CD ROM.

ALVES, A. E. L.; SILVA, F. M.. Poluição do ar e saúde nos principais centros comerciais da cidade de Natal/ RN. Holos, Natal, v. 4, p.81-95, 2009.

ANDRADE, C. S. Representações do Calor em Teresina-PI. (Dissertação de Mestrado). Recife: Programa de Pós- Graduação em Geografia-UFPE, 2000. 174p.

ANDRADE, C. S. A climatologia da cidade de Teresina-PI: as variantes topoclimáticas dos espaços livres. (Tese de Doutorado). Recife: Programa de Pós- Graduação em Geografia-UFPE, 2009. 100p

ANDRADE, H. Clima urbano: natureza, escalas de análise e aplicabilidade. Finisterra, Revista Portuguesa de Geografia, XL, 80, p.66-91, 2005.

ANDRADE, H. O; SANTO, S.M; SANTOS, R.L. A condição termal em Feira de Santana/BA: uma análise do conforto térmico. In: Anais do IX Simpósio Brasileiro de Geografia Física Aplicada. Natal/RN, 2007. CD-ROM.

ANDRADE, H. O; SANTOS R.L. Estimativa de conforto térmico a partir do índice de Thom (1959) para a cidade de Feira de Santana/BA. In: Anais do VII Simpósio Brasileiro de Climatologia Geográfica. Rondonópolis/MT, 2006. CD- ROM.

ARAÚJO, R. R. O processo de urbanização na produção do clima urbano de São Luís-MA. (Dissertação de Mestrado). Presidente Prudente/SP: Programa de Pós-Graduação em Geografia/UNESP-PP, 2001. ARAÚJO, R. R; SANT'ANNA NETO, J. L. O processo de urbanização na produção do clima urbano de São Luís-MA. p.21- 41. In: SANT'ANNA NETO, J. L. (Org). Os Climas das Cidades Brasileiras. Presidente Prudente: UDUNESP, 2002. 227p.

ARAÚJO, R. R. ET AL. Estudos preliminares do comportamento termo-higrométrico em áreas urbanas de São Luís/MA. In: Anais do IV Simpósio Brasileiro de Climatologia Geográfica. Rio de Janeiro, 2000. CD ROM.

ARAÚJO, R. R. ET AL. Considerações preliminares sobre a influência da tipologia do uso do solo no clima local em quatro áreas de São Luís-Maranhão. Ciências Humanas em Revista-UFMA, São Luís, v. 1, n. 2, p.125-134, 2003.

ARAÚJO, R. R. Bioclimatologia urbana e conforto térmico em São Luís. Ciências Humanas em Revista -UFMA, São Luís, v. 7, p.1-9., 2009.

ARAÚJO, T. L. Estimativa da temperatura e do saldo de radiação à superfície terrestre em Maceió-AL utilizando imagens TM/LANDSAT (Dissertação de Mestrado). Maceió: Programa de Pós- Graduação em Meteorologia-UFAL, 2006.88p.

BARBOSA, R. V. R. Áreas verdes e qualidade térmica em ambientes urbanos: estudo em microclimas de Maceió/AL. (Dissertação de Mestrado). São Paulo: Programa de Pós Graduação em Arquitetura USP/ EESC, 2005. 135p

BRASIL. Ministério da Educação. Coordenação de Aperfeiçoamento de Pessoal de Nível Superior - CAPES. Documento de Área Geografia 2013. Disponível em: http:/www.avaliacaotrienal2013.capes.gov.br/ documento-de-area-e-comissao. Acesso em 30/11/2013.

CARVALHO, M. M. Clima urbano e vegetação: estudo analítico e prospectivo do Parque das Dunas em Natal/RN. (Dissertação de Mestrado). Natal: Programa de Pós Graduação em Arquitetura e Urbanismo-UFRN, 2001. 288p.

CASTRO, M. S. G. Influência do clima no planejamento urbano e análise do comportamento termohigrométrico do Conjunto Habitacional Ponta Negra/ RN. (Dissertação de Mestrado). São Paulo: Programa de Pós-Graduação em Arquitetura e Urbanismo- USP/EESC, 1991. 178p. 
COSTA, J.R.S; SILVA, F. M.; BEZERRA. Conforto térmico na cidade de Natal e Ceará-Mirim/RN utilizando os métodos de ITU e WCI. Okara: Geografia em Debate, João Pessoa, v. 3, p.241-253, 2009.

DUARTE, M. L.F. Comportamento Microclimático Urbano: Estudo de caso de um recorte urbano em João Pessoa-PB. (Dissertação de Mestrado). João Pessoa/PB: Programa de Pós-Graduação em Arquitetura e Urbanismo /UFPB, 2010.

ELY, D. F. Teoria e método da climatologia geográfica brasileira: uma abordagem sobre seus discursos e práticas. (Tese de Doutorado). Presidente Prudente/SP: Programa de Pós-Graduação em GeografiaUNESP-PP, $208 \mathrm{p}$.

FEITOSA, S. M. R. Alterações climáticas em Teresina-PI decorrentes da urbanização e supressão de áreas verdes. (Dissertação de Mestrado). Teresina/PI: Programa Regional de Pós- Graduação em Desenvolvimento e Meio Ambiente PRODEMA- UFPI, 2010. 112p.

FEITOSA, S. M. R. ET AL. Consequências da urbanização na vegetação e na temperatura da superfície de Teresina- Piauí. Revista da Sociedade Brasileira de Arborização Urbana, v.6, p.58-75, 2011.

FIALHO, E. S; AZEVEDO, T. R. Análise da produção científica dos estudos climatológicos a partir da criação do SBCG (1992-2004). In: Anais do VII Simpósio Brasileiro de Climatologia Geográfica. Rondonópolis/MT, 2006. CD ROM.

FREITAS, R Clima urbano na cidade do Recife ou arquipélago das Ilhas concêntricas. In: Anais do VI Simpósio Brasileiro de Climatologia Geográfica. Aracaju/SE, 2004. CD ROM

GONÇALVES, N. M. S. Impactos pluviais e desorganização do espaço urbano em Salvador/BA. (Tese de Doutorado). São Paulo: Programa de Pós-Graduação em Geografia Física-FFLCH/USP, 1992. 268p.

GONÇALVES, N. M. S. Impactos pluviais e desorganização do espaço urbano em Salvador. p.69-92. In: MONTEIRO, C. A F.; MENDONÇA, F. (Orgs). Clima Urbano. São Paulo: Editora Contexto, 2003.192p.

GONÇALVES, N. M. S. Aspectos do clima urbano de Salvador: uma análise da intensidade das chuvas e suas conseqüências socioespaciais. Revista do Instituto Geográfico e Histórico da Bahia, Salvador, v. 99, p. 255-267, 2004.

IBGE. Sinopse do Censo Demográfico 2010. Disponível em: http://www.ibge.gov.br. Acesso em 05/10/2012.

IMAMURA-BORNSTEIN, I.R. Observational studies of urban heat island characteristics in the different climate zones. (Phd These). Tsukuba: University of Tsukuba, 1991.

JÚNIOR. I. F. S. A influência da urbanização no clima da cidade de Campina Grande-PB (Dissertação de Mestrado) Campina Grande: Programa de Pós-Graduação em Meteorologia-UFCG, 2006.

KALLAS, L.M.E. Desenhando com o clima e a vegetação: um estudo de caso do loteamento HBB em Teresina- PI. (Dissertação de Mestrado). Brasília: Programa de Pós- Graduação em Arquitetura e Urbanismo- UnB/IAU, 2008. 167p.

LEITE, R. C. V; SILVA, A. C. Microclimas e vias urbanas: estudo de caso em Fortaleza. In: Anais do IX Simpósio Brasileiro de Climatologia Geográfica. Fortaleza/CE, 2010. CD ROM.

LOMBARDO, M. A. Algumas considerações sobre os estudos de clima urbano no Brasil. p. 93 - 108. In: ALCOFORADO ET. AL. (Org.) Estudos sobre Cidades e Alterações Climáticas, Lisboa, 2008.

LUNA, J. B; CARVALHO, G. R. S; DO AMARAL, R. F. O figura termal do Campus Central da UFRN por extensão “3D”. In: Anais do VII Simpósio Brasileiro de Climatologia Geográfica. Rondonópolis/MT, 2006. CD ROM.

MAIA, L.P ET AL. Alterações climáticas na região de Fortaleza causada por fatores naturais e antrópicos. Revista de Geologia UFC, Fortaleza, vol. 9, p.111- 121, 1996.

MALVEIRA, E. C. H. Estudo de Mudanças Climáticas num ambiente urbano: Evolução da Ilha de Calor na Região Metropolitana de Fortaleza. (Dissertação de Mestrado). Fortaleza: Programa de Pós-Graduação em Geografia- UECE, 2003. 191p.

MELO, G. A utilização dos recursos auxiliares do condicionamento térmico natural na elaboração e avaliação de projetos de habitações em Natal/RN. (Dissertação de Mestrado). São Paulo: Programa de Pós-Graduação em Arquitetura e Urbanismo-USP/EESC, 1991. 193p. 
MENDES, A. F; SILVA, A. B; GONÇALVES, N. M. Estimativa da temperatura da superfície da cidade de Feira de Santana-BA a partir da imagem do satélite LANDSAT ETM+ canal 6. In: Anais do VI Simpósio Brasileiro de Climatologia Geográfica. Rondonópolis/MT, 2006. CD ROM.

MENDES, A. F; SILVA, A. B; GONÇALVES, N. M. Aspectos geoecológicos e sua influência na temperatura da superfície da cidade de Feira de Santana/BA. In: Anais do IX Simpósio Brasileiro de Geografia Física Aplicada. Natal, 2007. CD-ROM.

MENDONÇA, F. A. O estudo do clima urbano no Brasil: evolução, tendências e alguns desafios. p.175192. In: MONTEIRO, C. A F.; MENDONÇA, F. A. (Orgs). Clima Urbano. São Paulo: Editora Contexto, 2003.192p.

MENDONÇA, F; LIMA, N. R; PINHEIRO, G. M. Clima Urbano no Brasil: Análise e contribuição da metodologia de Carlos Augusto de Figueiredo Monteiro. Revista GeoNorte, v. 1, p. 626-638, 2012.

MESQUITA, E. P; GRANGEIRO, C. G. M. A poluição do ar e a cidade metorizada: o caso do bairro do Centro. Anais do IX Simpósio Brasileiro de Geografia Física Aplicada. Natal, 2007. CD-ROM.

MONTEIRO, C. A. F. Teoria e Clima Urbano. Série Teses e Monografias, nº25. São Paulo: Instituto de Geografia/USP, 1976.181p.

MOREIRA, E. B. M. Análise dos topoclimas urbanos de Recife: o caso dos bairros de Santo Amaro e Curado. In: Anais do VII Encontro Nacional da ANPEGE. Niterói/RJ, 2007. CD ROM.

MOREIRA, E. B. M.; NÓBREGA, R. S. Uso de imagens multiespectrais aplicada à análise espaço-temporal dos padrões de temperatura e albedo da superfície. In: XV Simpósio Brasileiro de Sensoriamento Remoto, Curitiba/PR, 2011. CD ROM.

MOREIRA, E. B. M.; NÓBREGA, R. S. Identificação do fenômeno ilhas de calor urbano na área urbana do Recife, através do canal infravermelho termal do satélite LANDSAT. In: XV Simpósio Brasileiro de Sensoriamento Remoto, Curitiba/PR, 2011. CD ROM.

MOURA, M. O. Os microclimas urbanos de Fortaleza: ritmos episódicos em duas áreas representativas da cidade. (Monografia de Graduação). Fortaleza: Departamento de Geografia-UFC, 2006. 168p.

MOURA, M. O. O clima urbano de Fortaleza sob o nível do campo térmico. (Dissertação de Mestrado). Fortaleza: Programa de Pós- Graduação em Geografia-UFC, 2008. 318p

MOURA, M. O.; ZANELLA, M .E; SALES, M. C. L. Ilhas térmicas na cidade de Fortaleza/CE. Boletim Goiano de Geografia, vol.28, n.2, jul-dez, Goiânia, p.33-44, 2008.

MOURA, M. O; ZANELlA, M. E, SALES, M. C. L. Conforto Térmico em Fortaleza-CE. Revista da ANPEGE, v.6, p.177 - 189, 2010.

MOURA, M. O; THIERS, P. Estimativa da temperatura da superfície urbana de Fortaleza utilizando imagem LANDSAT 5TM. In: IX Simpósio Brasileiro de Climatologia Geográfica. Fortaleza/CE, 2010. CD ROM. MOURA, T. ET AL. Mapeando as condições de conforto térmico em Salvador . RUA (Revista de Arquitetura e Urbanismo- UFBA), Salvador, vol.7, n.1, Salvador, p.44-49, 2006.

NERY, J. T; ANDRADE,T; MOURA, T. Conforto térmico em Salvador: o índice PET e sua abordagem projetual. RUA (Revista de Arquitetura e Urbanismo- UFBA), vol.7, n.1, Salvador, p.70-77, 2006.

NÓBREGA, R. S; VITAL, L. A. B. Influência da Urbanização sobre o microclima de Recife e formação de ilha de calor. Revista Brasileira de Geografia Física, Recife, v. 3, p. 151-156, 2010.

NÓBREGA, R. S.; LEMOS, T. V. S. O (des)conforto térmico em ambientes abertos na cidade de Recife: um estudo microclimático. Revista de Geografia, Recife, v. 28, p. 93-109, 2011.

OLIVEIRA, G. C. S. ET AL. Uma abordagem da geografia do clima sobre os eventos extremos de precipitação em Recife PE. Revista Brasileira de Geografia Física, Recife, v. 4, p. 9-23, 2011.

OLIVEIRA, E.D; SILVA, F.M. Diagnostico do conforto térmico entre praças com características geográficas distintas em Natal/RN. In: Simpósio Internacional de Climatologia. Fortaleza: SBMET/FUNCEME, 2005. CD-ROM.

ONU/ BANCO MUNDIAL. Relatório sobre o Desenvolvimento Mundial de 2010: Desenvolvimento e Mudança Climática (Tradução Ana Luiza Iaria). São Paulo: Editora UNESP, 2010. 440p. 
PAIVA, J. P. M. Análise Microclimática em Conjuntos Habitacionais: o caso do Conjunto Ceará- Fortaleza/CE. (Dissertação de Mestrado). Fortaleza: Programa de Pós-Graduação em Geografia-UECE, 2010. $150 \mathrm{p}$.

PAIVA, F. I. B. Microclimas urbanos na área central do bairro da Messejana, Fortaleza/CE. (Monografia de Graduação). Fortaleza: Departamento de Geografia-UFC, 2011. 89p.

PÉLALAS, K.V. Impactos sobre os parâmetros climáticos em duas áreas de Fortaleza-Ce. (Dissertação de Mestrado). Fortaleza: Pós-Graduação em Engenharia Civil-UFC, 2000.

PONTES, C.M.F ET AL. Mapeamento da qualidade do ar no bairro da Várzea (Recife/PE), utilizando liquens como bioindicadores. Anais do IX Simpósio Brasileiro de Geografia Física Aplicada. Recife, 2001. CD-ROM.

PROJETO METROFOR. Estudo microclimático da área central de Fortaleza. Volumes 1 e 2. Fortaleza: Prefeitura Municipal de Fortaleza, 1990.

PINTO, J. E. S. S. O clima local de Aracajú- SE. p. 43-60. In: João Lima Sant' Anna Neto. (Org.). Os climas das cidades brasileiras. Presidente Prudente: EDUNESP, 2002, 227p.

ROCHA, ET. AL. Elementos climatológicos e dispersão de poluentes atmosféricos em ambiente urbano. In: IX Simpósio Brasileiro de Climatologia Geográfica. Fortaleza/CE, 2010. CD ROM.

SAMPAIO, A. H. L. Correlações entre o uso do solo e ilha de calor no ambiente urbano: o caso de Salvador/BA. (Dissertação de Mestrado). São Paulo: Programa de Pós Graduação em Geografia FísicaFFLCH/USP, 1981.

SANTANA, A. M. S. O desenho urbano e a climatologia em Fortaleza. (Dissertação de Mestrado). São Paulo: Programa de Pós Graduação em Geografia Física-FFLCH/USP, 1997.168p.

SANTANA, A. M .S. A forma urbana e a radiação solar incidente na criação das ambiências térmicas e seus reflexos na apropriação e uso dos espaços públicos externos. (Tese de Doutorado). São Paulo: Programa de Pós-Graduação em Geografia Física- FFLCH/USP, 2002. 292p.

SANTOS, C. O; PINTO, J. E. S. S. Consciência ambiental, princípios e indicadores de qualidade de vida: um estudo no campo da climatologia urbana. Revista ABCLIMA, ano 6, vol. 7, p.46- 61, 2010.

SANTOS, J. S. Campo térmico urbano e sua relação com o uso e cobertura do solo em João Pessoa. (Tese de Doutorado). Campina Grande: Programa de Pós- Graduação em Recursos Naturais-UFCG, 2011. SARAIVA, A. L. B. C; GRIGIO, A. M.; MOURA, S. R. F. Estudo do campo térmico da cidade de Mossoró- RN: episódio de outono. In: IX Simpósio Brasileiro de Climatologia Geográfica. Fortaleza/CE, 2010. CD ROM.

SILVA, A. P. L. M. ET AL. Avaliação de microclimas urbanos na cidade de Patos. In: I Simpósio Internacional de Climatologia. Fortaleza, 2005.CD ROM.

SILVA, A. P. L. M. ET AL. Avaliação de microclimas urbanos na cidade de Campina Grande no período do verão. In: I Simpósio Internacional de Climatologia. Fortaleza, 2005. CD ROM.

SILVA, J.B. A pesquisa e a produção geográfica. Revista da ANPEGE, v.7, número especial, p.135 - 146, 2011.

SILVA, N. T. ET AL. Avaliação do conforto térmico no centro urbano de João Pessoa-PB. In: IV Simpósio Internacional de Climatologia. João Pessoa/ PB, 2011. CD ROM.

SOUSA, R.M; LUNA, J.B; CARVALHO, G. R. S. Ventilação e prescrição urbanística: um caso de estudo para Natal/RN. In: Anais do VII Simpósio Brasileiro de Climatologia Geográfica. Rondonópolis/MT, 2006. CD ROM.

SOUZA. V.S. Figura de análises climáticas urbanas da cidade de João Pessoa-PB. (Dissertação de Mestrado). João Pessoa: Programa de Pós-Graduação em Arquitetura e Urbanismo -UFPB, 2010.

TARIFA, J.R; VASCONCELLOS, R. The local climate of São Luís Island, an environmental approach. In. International Geographical Union Latin-American Regional Conference. São Paulo,1982.(Impresso). TORRES, S. C; BARBIRATO, M. G. O conforto ambiental de espaços públicos urbanos em conjuntos habitacionais em Maceió/AL. In: Anais do III Congresso do Meio Ambiente. Salvador, 2004. CD ROM. 
VALADÃO. Variabilidade climática a temperatura do ar na região de Natal/RN. IX Simpósio Brasileiro de Climatologia Geográfica. Fortaleza/CE, 2010. CD ROM.

VIDAL, R. Influencia da morfologia urbana nas alterações da temperatura do ar na cidade de Natal. (Dissertação de Mestrado). Brasília: Programa de Pós Graduação em Arquitetura e Urbanismo- UnB/IAU, 1991.

XAVIER, T.M.B.S. Alterações climáticas urbanas em Fortaleza/CE. In: IX Congresso Brasileiro de Meteorologia. Campos do Jordão: SBMET, 1996.

ZANELLA, M.E; SALES, M. C. L; ABREU. N. J. Análise das Precipitações diárias intensas e impactos gerados em Fortaleza-CE. GEOUSP. São Paulo, v. 25, p. 53-68, 2009.

ZANELLA, M.E; SILVA, N.G.S. Eventos pluviométricos intensos em ambiente urbano: Fortaleza, episódio do dia 29/01/2004. p.195-207 .In: SILVA, J.B; DANTAS, E.W.C; ZANELLA, M.E; MEIRELES, A.J.A. (Orgs.).

Litoral e Sertão: natureza e sociedade no nordeste brasileiro. Fortaleza: Expressão Gráfica, 2006. 446p.

ZANELLA, M.E; CLAUDINO-SALES, V. Considerações sobre o clima urbano frente às emendas propostas à lei do uso e ocupação do solo na cidade de Fortaleza-CE. In: Anais do V Simpósio Brasileiro de Climatologia Geográfica, 2002. CD ROM.

Trabalho enviado em novembro de 2012 Trabalho aceito em janeiro de 2013 